\title{
Creating A Culture Of Academic Assessment And Excellence Via Shared Governance
}

E. George Beckwith, National University, USA

Susan Silverstone, National University, USA Debra Bean, National University, USA

\begin{abstract}
When a recent accreditation review report and an assessment consultant report both identified issues with assessment and shared governance, the three faculty governing bodies of National University met with the Provost and President to brainstorm and discuss a shared governance action plan to address these issues. As a result of this meeting, the Faculty Senate, Graduate Council, Undergraduate Council, and the Council of Chairs (not a governing body) representatives made a presentation to the Provost and President to improve the academic assessment process at the University by implementing a shared governance plan that would revitalize the faculty and move both the faculty and the administration toward a culture of academic assessment and excellence. The President concurred with the shared governance assessment plan approach proposed by the faculty governing bodies and approved implementation of the plan. This paper explores relevant research on this subject and provides a chronology of the events that comprised the efforts to improve shared governance between the faculty and the administration at National University in order to achieve academic assessment and learning excellence.
\end{abstract}

Keywords: shared governance, culture of excellence, assessment, learning excellence

\section{INTRODUCTION}

e n February 2008, a Western Association of Schools and Colleges (WASC) team visited National University for a capacity and preparatory review followed by phone interviews between commission members and NU officials. In June, 2008, National University received a letter from the commission summarizing the visit to include what they thought NU was doing well as well as areas where they thought NU could improve.

In June 2008, the Dean of the School of Media and Communication, was promoted to the office of Associate Provost with the charge to focus on National University's Assessment process to include addressing the comments and recommendations of the WASC Action Letter. One of the Associate Provost's initial actions was to enlist the consultant services of Mary Allen, Ph.D. a published author and widely recognized expert on Assessment programs in higher education. Dr. Allen met with both faculty and administration representatives to obtain information on the existing assessment program at National University. These faculty and administration assessment representatives included:

- $\quad$ The Faculty Senate Chair

- $\quad$ The Graduate Council Chair

- The Council of Chairs

- $\quad$ The Graduate Council Assessment Committee Chair

- $\quad$ The Undergraduate Council Assessment Committee Chair 
- $\quad$ The University Academic Assessment Committee

- $\quad$ The School Deans

- $\quad$ The Associate Vice President for Institutional Research, Planning and Analysis (IRPA)

- $\quad$ The Associate Provost

- $\quad$ The Provost and President

As a result of the information gathered during these meeting discussions, the Assessment Consultant submitted a formal report entitled Review of National University Assessment and WASC Educational Effectiveness Preparation. This report was disseminated to all participants of the discussion and information sessions on which the report was based as well as the Chairs of the three faculty governing bodies-The Faculty Senate, the Graduate Council, and the Undergraduate Council. The President called a meeting with representatives of the Faculty Governing Bodies and the Provost, Associate Provost, and the Associate VP OIRA to discuss the feedback received from both the WASC review visit letter and Dr. Allen's report in order to develop a plan of action for restructuring the National University Assessment Program using the letter and report as a guide.

The chairs of the three faculty governing bodies, supported by the council of chairs, proposed that the chairs of the Graduate Council Assessment Committee and the Undergraduate Council Assessment Committee develop an NU Assessment Action Plan to be presented to the Graduate and Undergraduate Councils for initial approval and presentation to the Provost and President for final approval. The proposed plan, included actions to address the recommendations contained in the WASC letter and the Assessment Consultant's report-- which included input from the Council of Chairs, the Deans, the Graduate Council, the Undergraduate Council, the University Academic Assessment Council, the AVP OIRA, the Associate Provost, and the Provost—was coordinated with all concerned and disseminated to the full faculty at the fall assembly. The President concurred with the assessment plan approach proposed by the faculty governing bodies and requested that they periodically update her on the progress.

Literature Review

\section{LITERATURE REVIEW}

\section{Shared Governance as a Basic Principle}

Larry Gerber (2009) stated that the constituencies of an institution of higher education are not all equally positioned to make sound judgments about what is appropriate or necessary regarding teaching and research. The 1966 Statement on Government of Colleges and Universities, which remains the American Association of University Professor's (AAUP) principal policy document on the issue, premises its defense of shared governance on the assumption that faculty ought to exercise "primary responsibility for such fundamental areas as curriculum, subject matter and methods of instruction, research, faculty status, and those aspects of student life which relate to the educational process," because the faculty — not students, administrators, or boards of trustees - have the greatest expertise in these matters. Gerber (2009) also notes that colleges and universities, when making decisions regarding teaching and research, should make them on the basis of academic criteria and not on the basis of external political pressures or arbitrary administrative fiat. He further concludes that faculty expertise - often residing in an individual, but also expressed at times in a collective fashion, should be the determining factor in institutional decisions affecting academic matters.

\section{Educational Goals and Measurement}

Establishing educational goals and then measuring the success in achieving those goals is a normal approach by many in the educational system (Gerber, 2009). The problem arises, he concludes (Gerber, 2009) when those that are not actually involved in teaching or research gain control over the assessment process and insist on standards that are more appropriate for evaluating consumer products in the business world than for evaluating the quality of education teachers should be providing to their students. A factor that arises between the faculty and the administration, particularly regarding issues of academic learning and assessment programs, pertain to the program review locus of control which depends largely on whether the review is internal or external (Baker, 2005). There is usually more control in the case of the internal review since this is usually done as cooperative effort between the faculty and administration. 
Depending on how academic entities at a given institution are structured, the essential participants in any graduate program review are the academic vice president, the college or school dean, the graduate dean, the department chair, the graduate program faculty, the review committee or committees, and graduate students in the program (Baker, 2005). Baker (2005) concludes that all of the above must be involved if the review is to succeed. There is less control over external reviews since such reviews are done by agencies outside of the university but the normal contact is usually an administrator rather than a faculty member but it could be argued that since this arrangement places the review conclusions and related academic program information in the hands of the administration first before faculty review, control shifts in favor of the administration.

\section{Assess to Institutional Data}

Another area of possible contention between the faculty and the administration is the access to institutional data. Accurate institutional data is essential to successful reviews and it follows that data on academic programs should be developed, stored, and maintained centrally but such data must be reviewed and evaluated by program faculty to insure its accuracy and relevancy (Baker, 2005). The ideal, according to Baker (2005), is to have a central office, funded by the administration, which works closely with the faculty to gather and maintain the data to insure that there is sufficient data to support a program review. Finally, in cases where there are many offices that contain critical data needed for a program review, such as admissions, faculty records, contract and grant information, Baker (2005) recommends that a central data base should be created strictly for program review purposes with the data in a standard agreed upon format.

Allen (2004) observes, however, that data that is filed away and is not used for academic program analysis is useless, a direct criticism of those faculty and institutions that are "wonderful data collectors" but who do not analyze the data for information that could help them improve the academic programs. She believes that the data has to be analyzed by the faculty in order to reach conclusions about what the assessment of the data means in order to determine the implications for changes in the curriculum or pedagogy and related program modifications.

\section{Balancing Academic Shared Governance}

A good balance between the faculty and administration governing bodies is critical to the smooth functioning of a university. Tierney (2004) concluded that governance is the primary method to implement ideas that either respond to problems or provide new strategies. He (Tierney (2004) continues to state that when academic governance is not effective, it should be reformed. The shape of those reforms is what the authors of this volume consider.

The American Federation of teachers concluded (2009) believes that strengthening shared governance is a responsibility of all universities and colleges and is critical to the academic integrity of both in order to guard against the pressures of commercialization from distorting an institution's educational mission or eroding standards and quality. It is also necessary to preserve the ideals of academic freedom and democratic practice.

Mortimer and Sathre (2007) found that the model of shared governance between faculty and administrators does not always work with the realities of decision making in the academic environment of today because of the external and internal forces that affect how governance is accomplished. Controversial issues such as tuition setting, resource allocation, institutional planning, program closures, and multi-campus relationships are major areas of conflict.

\section{Faculty Governance Structures}

Campus senates (AAUP, 1995) are the most common mechanism systematic faculty involvement in governance and the AAUP found that usually, the faculty in each college or school elects the senators making the campus senate a representative body. The majority of campus senates perform their functions primarily through committees; these committees are only allowed to make recommendations to the president/administration and board about institutional matters (AAUP, 1995). Several campuses have developed other formal governance structures in order to codify decision-making processes and input but other campuses have developed joint committees of faculty, 
students, and administrators that provide recommendations for action on key institutional issues (AAUP, 1995).

Another problem that can arise to cause a problem for shared governance, particularly in the area of academic learning and assessment, is the lack of a common way of thinking about and a common vocabulary for talking about these two areas of mutual interest (Anderson et al, 2001). A solution, according to Anderson (2001) is to develop a framework that broaches this gap and provides some commonality in thinking and vocabulary that can be shared by instructors, curriculum coordinators, assessment specialists and administrators.

\section{Assessment Culture, Politics, and Policies}

In cases where the culture, politics and policies tilt power and control toward the administration, the faculty may not be actively engaged in using assessment to enhance learning. Allen (2004) references the Association of American Colleges and Universities (AACU) who concluded that engagement of program faculty in assessment is essential for the assessment process to be successful. The AACU further concluded that campus policies should reward and encourage faculty participation in the assessment process. Accrediting agencies not only suggest the involvement of faculty in the assessment process but require it. Allen (2004) found that often faculty fear that their unfavorable conclusions about a given program resulting from an analysis of assessment data could result in punishment by deans or provosts rather than being rewarded by them for finding program problems that need attention. This is where faculty must have faith in the shared governance model and believe that the Senate and Graduate and Undergraduate Councils will speak up on their behalf and protect them.

\section{IMPLEMENTING A NEW SHARED GOVERNANCE LEARNING AND ASSESSMENT MODEL}

As noted in the Introduction, the chairs of the three faculty governing bodies, supported by the council of chairs, proposed that the chairs of the graduate council assessment committee and the undergraduate council assessment committee develop a Shared Governance NU Assessment Action Plan to be presented to the NU Graduate and Undergraduate Councils for initial approval and presentation to the provost and president for final approval. The proposed plan was approved and implemented as follows.

This plan contained a list of the major concerns and recommended action items noted in the June WASC Commission's letter to the University as well as those noted by the July Assessment Consultant's (Dr. Mary Allen) report to include an action plan and commensurate timeline to address them. It also described the assessment structure and assessment process to be used in implementing the plan. The list, noted above from WASC and Dr. Allen's report is contained in subsequent pages. A proposed timeline for the implementation of this plan is provided below and is followed by a proposed diagram of the NU Assessment Structure (see Figure 1).

- $\quad$ August 20: Assessment Plan approved by the President.

- September 3: Plan overview presented to administration and faculty at the Fall Assembly.

- $\quad$ September 10: Interim CAA Faculty Members selected.

- $\quad$ September 15-30: Series of Three-day Assessment Workshops by Assessment Consultant with Program Lead Faculty members, Chairs, GC \& UGC Assessment Committees, SACs, the Assistant Provost, CAA members, and AVP OIRA to review this Assessment Plan and discuss how each action item from the WASC letter and Dr. Allan's report will be addressed to include how, who, what, and when.

- $\quad$ October 6-31: All Lead Program Faculty, in consultation with Department Chairs and SACs, develop a program plan to incorporate program and institutional level assessment.

- $\quad$ November 08 - January 09: Assessment rubrics and measures will be developed by Program Lead Faculty with assistance from Chairs and SACs. Department retreats will be funded to insure that adequate time is available to complete this critical and essential work.

- February 09: All program assessment plans will be reviewed and approved by the Graduate or Undergraduate Council.

- March 09: AMS Data collection using the newly developed rubrics and measures will begin for all programs.

- $\quad$ April-May 09: AMS Program review rubrics will be developed and tested for Chairs, SACs, Deans, GC \& UGC Assessment Committees to insure standard, quality assessment review of all programs. 
- $\quad$ September 25, 09: AMS PAR Data by Program Lead Faculty due.

- $\quad$ September 28-October 9, 09: AMS PAR Data review by Chairs with comments due.

- $\quad$ October 12-23, 09: AMS PAR Data review by SACs with comments due.

- $\quad$ October 26-November 6, 09: AMS PAR Data review by Deans with comments due.

- November 9-20, 09: AMS PAR Data and all subsequent review comments review by Graduate and Undergraduate Council Assessment Committees for presentation to councils at first meeting in December.

- January 2010: GC and UGC Assessment Committees provide a presentation summarizing the assessment program reviews to include areas of concern that require further action noting those that require resources that should be given priority support during the upcoming budget process.

Figure 1: National University Academic Governance Organizational Chart

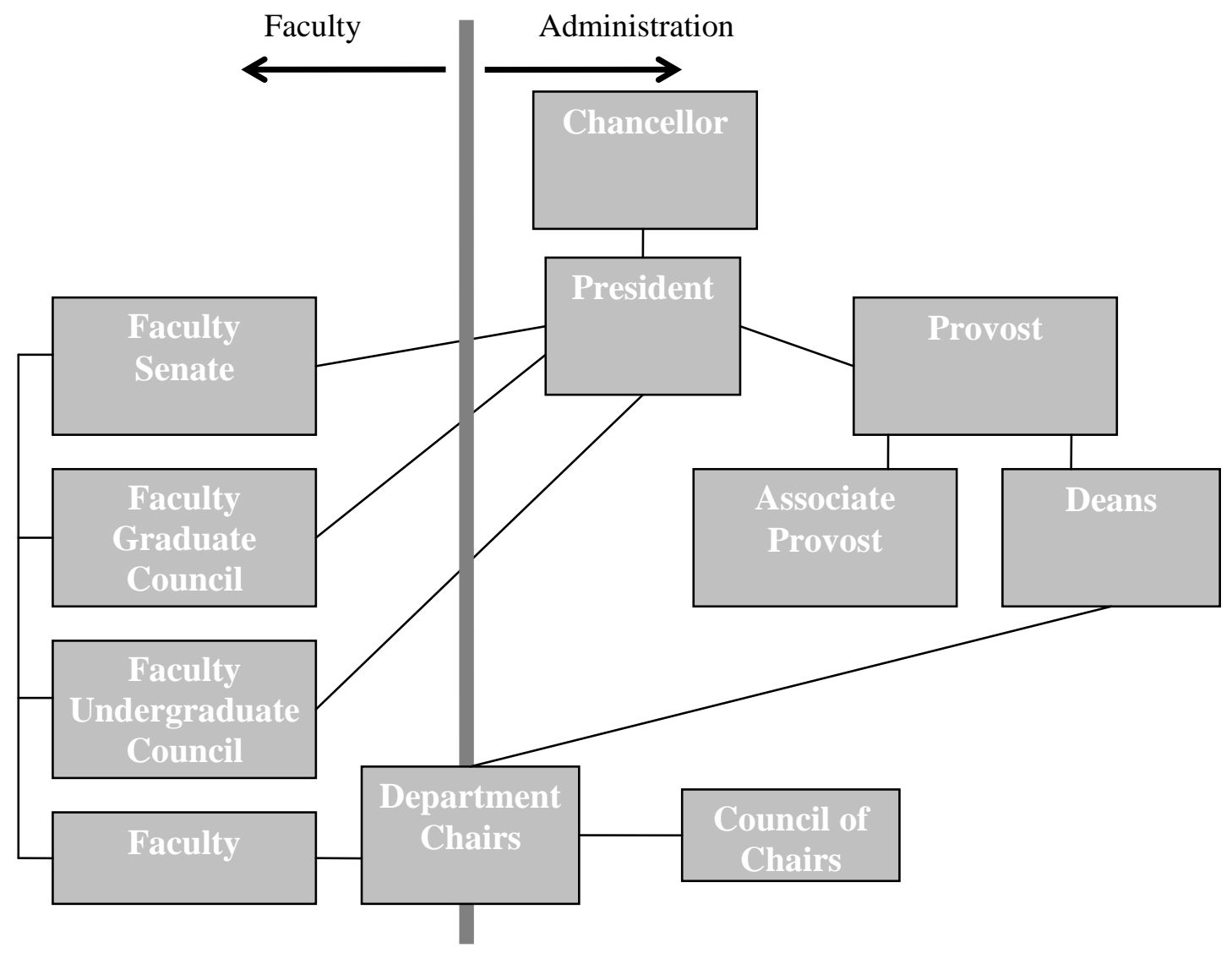

\section{Plan Objective}

The objective of this shared governance academic assessment plan is three fold. First, to address concerns and implement the recommendations contained in the WASC letter and the Assessment Consultant's report. Second, to revise the academic assessment process by better utilization of the data collection and presentation capabilities of the Accountability Management System (AMS). The AMS allows the lead faculty, who input the assessment data, and all assessment review bodies to review the data on online. Third, to develop a long range academic assessment plan that not only promotes a shared faculty-administration governance partnership in using assessment to insure that learning and teaching are meeting the aim and purpose of the University, but also creates a 
culture of assessment among all concerned.

\section{Action Items Based on the Concerns and Recommendations from the WASC Letter and Assessment Consultant's Report}

WASC Letter

1. Item: Show more reflection, analysis, and synthesis of direct and indirect evidence of student learning at course, program and institution levels.

Action: (To be developed in off-site retreats with consultant)

2. Item: Document educational effectiveness across various student groups.

Action: (To be developed in off-site retreats with consultant)

3. Item: Provide more data analysis input by faculty that is documented and disseminated in appropriate cycles.

Action: (To be developed in off-site retreats with consultant)

4. Item: Develop a decision process to identify data to be collected and how it will be used for improvement.

Action: (To be developed in off-site retreats with consultant)

5. Item: Provide both direct and indirect evidence of student learning and how it is reviewed, analyzed, and applied to insure that students are achieving learning outcomes.

Action: (To be developed in off-site retreats with consultant)

6. Item: Show that faculty, at the course, program, and institutional levels are responding to the findings of evidence.

Action: (To be developed in off-site retreats with consultant)

7. Item: Investigate and provide evidence of the investigation and resultant action of whether or not access for different student populations vary-i.e. retention, graduation rates for transfer vs. native students and for students of various socioeconomic and demographic groups.

Action: (To be developed in off-site retreats with consultant)

8. Item: Investigate and analyze the composition of students versus the composition of faculty and the impact, if any, of the similarity or differences.

Action: (To be developed in off-site retreats with consultant)

9. Item: Investigate and analyze what additional resources and attention should be devoted to professional development, teaching effectiveness, and adjunct faculty.

Action: (To be developed in off-site retreats with consultant)

10. Item: Investigate what additional data may need to be collected and analyzed to show evidence of the teaching effectiveness, participation, and faculty development participation, and leadership opportunities of part time faculty. 
Action: (To be developed in off-site retreats with consultant)

11. Item: Develop processes and activities that provide evidence of shared governance between the faculty and the administration to include administration support of faculty leadership responsibilities.

Action: (To be developed in off-site retreats with consultant)

\section{Assessment Consultant's Report}

1. Item: Develop institutional learning objectives and a plan for their assessment.

Action: (To be developed in off-site retreats with consultant)

2. Item: Provide time and resources to faculty so they can do effective assessment.

Action: (To be developed in off-site retreats with consultant)

3. Item: Provide more training and support for effective program-level assessment.

Action: Sponsor retreats for lead faculty and chairs

4. Item: Substantially reduce the number of variables included in the PARs.

Action: (To be developed in off-site retreats with consultant)

5. Item: Prepare all programs to respond to the questions and criteria in the WASC EE Visiting Team rubrics.

Action: (To be developed in off-site retreats with consultant)

6. Item: Include retention and graduation rates in program reviews, including disaggregating these variables by ethnicity, sex, and when relevant, format (on-site vs. on-line).

Action: (To be developed in off-site retreats with consultant)

7. Item: Refine General Education outcomes and develop and implement a multi-year plan for their assessment.

Action: (To be developed in off-site retreats with consultant)

8. Item: Provide stipends to adjuncts who assess student work in assessment projects.

Action: (To be developed in off-site retreats with consultant)

9. Item: Clarify the policy role of the UAC and who has to consider and approve their recommendations.

Action: (To be developed in off-site retreats with consultant)

10. Item: Establish targets for each program for each of the variables to be analyzed in the program review so faculty can determine if they are meeting or exceeding campus expectations.

Action: (To be developed in off-site retreats with consultant) 


\title{
WASC Letter and Assessment Consultant Report (ACR) Item Correlation
}

\author{
- $\quad$ WASC 1, ACR 3 \\ - WASC 3, ACR 2 \\ - WASC 4, ACR 10 \\ - $\quad$ WASC 5, ACR 10 \\ - WASC 6, ACR 5 \\ - $\quad$ WASC 7, ACR 6 \\ - $\quad$ WASC 9, ACR 2,3 \\ - WASC 10, ACR 8 \\ - $\quad$ WASC 11, ACR 10
}

Actions for these items can be integrated.

\section{Structure--Roles of the Faculty and Administration}

- $\quad$ Faculty Governing, Leadership, and Key Faculty Bodies

$\circ \quad$ Faculty Senate

Though the primary governing bodies for the academic assessment of learning effectiveness at National University rests primarily with the Graduate and Undergraduate Councils, the Faculty Senate supports a strong academic culture of learning assessment and seeks to enhance this culture by working with the administration to support the faculty in all matters pertaining to their welfare.

Faculty who are secure in an academic environment where all matters of merit, promotion, reappointment, pay/benefits are handled fairly, are better motivated to focus on the quality of their teaching and student learning to include meaningful assessment of both.

- Graduate Council and Undergraduate Councils

The Graduate Council and the Undergraduate Councils are the primary governing bodies charged with the oversight and support of Graduate and Undergraduate programs and education, respectively.

- $\quad$ Assessment Committees (AC)

These committees, each comprised of 5-7 faculty members, are the assessment arms of the Councils and are charged with reviewing the assessment programs of schools, providing assessment guidance, and assessment training on behalf of the Councils.

- It is the responsibility of the committees, working in coordination, to insure that all faculty members with a role in assessment are trained.

- Periodic training sessions and retreats will be held as appropriate to insure that assessment knowledge and expertise is current.

They will review the Program Annual Reviews (PAR) and the 5-year plans submitted by schools using standard rubrics approved by their respective councils.

The two committees will coordinate their efforts and consult each other regularly to insure that the assessment program is consistent across the University. 
The two committees will also coordinate their efforts and regularly consult with their respective Program Review Committees to insure that the review of programs consist of an assessment element while providing feedback on assessment analysis that impact course and program design and effectiveness.

- $\quad$ Program Review Committees (PRC)

The respective Program Review Committee (PRC) of each council is charged to assess proposed new, modified, and terminated programs on behalf of their councils to insure the programs are ready for Council consideration and/or approval.

The PRC's will use a rubric approved by their respective councils to insure all elements of academic rigor, quality, and support have been considered in the course/program design to include an assessment element to measure and provide evidence of student learning.

The PRC's will coordinate their efforts and regularly consult with their respective AC's to insure that the review of programs consist of an effective assessment element while obtaining feedback on assessment analysis that could impact course and program design and effectiveness.

$\circ \quad$ Council of Chairs $(\mathrm{CoC})$

Though not a governing body, the $\mathrm{CoC}$ plays a key leadership role at the University and in particular in the assessment progress.

In the visit by the Assessment Consultant, it was the CoC who surfaced many of the assessment support and process issues that the consultant, upon analysis and reflection, recognized needed to be addressed by the faculty and administration in order for the University to move to the next level of assessment.

It is also Department Chairs who supervise the Lead Program Faculty upon whom the majority of course and program assessment falls and therefore chairs are best suited to determine what support and resources are needed to insure program leads have the time and tools needed to do their assessment jobs effectively.

- School Assessment Committees (SAC)

SAC's assist the Deans in assuring quality of teaching and learning across the school and will use approved assessment rubrics in their review of AMS data provided by the program leads to include the review and comments by chairs.

SAC's will work closely with the GC \& UGC councils and will be represented at the University Academic Assessment Committee.

Upon initial appointment to the SAC, members will receive assessment training by a trained SAC member or upon request of the SAC Chair, by the GC/UGC Assessment Committee.

○ Program Lead Faculty

The most critical and vital group of people within the assessment process are the program leads who are directly responsible for the conception, development, design, maintenance, and assessment of programs and the courses that comprise them. 
Not only must they justify and obtain approval and/or modification for course and program approval but they must consistently work with instructors and subject matter experts (SME's) to insure and assess both the quality of teaching and learning.

Program Leads must receive initial and periodic assessment training to be conducted by the appropriate GC/UGC Assessment Committee member or designee.

○ Subject Matter Experts (SME)

Because of the large number of courses that comprise most academic programs, it is not reasonable or feasible for a given program lead to be an expert on each class, so it advisable for all program leads to designate a SME for each course in the program.

- A given faculty member may be a SME for several courses but each course in the program should have a SME.

- $\quad$ The program lead may be a SME but should limit the number of courses for which he/she is responsible commensurate with other program lead responsibilities.

- The course SME should also receive assessment training either by the program lead or upon the program lead request, by the GC or UGC Assessment Committee.

- Joint Faculty and Administration Body

○ The University Academic Assessment Committee (UAAC)

- The UAAC is a joint faculty and administrative body whose purpose is to insure assessment coordination and support across all levels of the University.

- It is comprised of the faculty representatives of the governing bodies (GC, UGC, Senate), a major faculty leadership body $(\mathrm{CoC})$, representatives from each of the SAC's, the IRPA, the Center for Academic Assessment (CAA), and the Associate Provost.

- Student, program lead faculty, and adjunct faculty representatives should be added to insure all levels of the assessment process are represented.

- School Deans, on a rotating basis, will be invited to attend meetings to insure their concerns are addressed and to inform them of on-going assessment issues and efforts.

- $\quad$ Administration

○ The Center for Academic Assessment (CAA)

The CAA will provide best practices learning and confidential support for faculty engaged in assessment of programs for continuous improvement of outcome based learning.

- $\quad$ This will include assisting program leads with the development of effective assessment rubrics as well as the review rubrics for use by chairs, SAC's, and deans.

It will work in conjunction with the GC and UGC Assessment Committees and assist these committees in their support of assessment training of faculty.

The CAA Chair will be fulltime position recruited and selected by a joint Faculty-Administration committee. 
While a search for the CAA Chair and supporting staff is being conducted, the Associate Provost in conjunction with the GC and UGC Assessment Committee Chairs will nominate interim faculty/staff for Provost approval to support the CAA.

Deans integrate the academic and administrative resources of the school to insure that the faculty has the guidance, direction, and support required to meet the teaching and learning goals and objectives of the school and the institution.

Deans will receive a coordinated AMS rubric to assist them in assessing the academic data in AMS.

The GC and UGC will provide, upon request, a knowledgeable member of one of the council's assessment committee members to update them on assessment training being provided to their faculty.

The Associate Vice President (AVP) for Institutional Research, Planning and Analysis (IRPA)

The AVP for IPRA and the IPRA staff play a key and critical role in both the efficiency and effectiveness with which the academic assessment data across the University is gathered, analyzed and used.

The Accountability Management System (AMS) is the input and repository of all National University academic and related data to be assessed and analyzed.

The AVP and ARPA staff will work closely with designated faculty members and administrative staff to insure the correct information is being provided for input into the system and that assessment rubrics are developed and used at all levels of academic assessment review to insure comprehensive and quality assessment of teaching and learning at National University.

The AP's role as the prime representative of the Provost in matters of academic assessment will interact and coordinate with all levels of faculty and administration in promoting a smooth operation of the assessment program across the University.

She is a member of the University Academic Assessment Committee and a welcome, invited guest, as appropriate, to participate in assessment discussions within the Graduate Council, Undergraduate Council, Council of Chairs, and the Faculty Senate to include support of and resources for the assessment program.

- Provost

As the chief academic, the Provost is responsible for administering the academic program, including both instruction and research, and for the coordination of the administrative and support functions of the University with its academic purposes.

He will meet, as appropriate to provide guidance and carry out his responsibilities, with any and/or all members of the assessment program noted above, to discuss assessment issues and insure all concerned are receiving the support and resources required for a successful assessment effort. 
○ President

The President provides oversight and coordinates all issues of the operation of the university from the scheduling of classes, student enrollment, faculty, policies and guidelines through to media issues.

This includes establishing, developing and monitoring the policies used in both academic and business aspects of the university.

To be successful in the responsibilities noted above, the president must preside over an effective and efficient academic assessment program that accurately measures the three areas of focus for the University:

- $\quad$ The Learner - Quality of Student Learning

- $\quad$ The Teacher-Quality \& Effectiveness of Teaching

- $\quad$ The Community-Collaboration \& Interaction

Toward this end, the GC and UGC in coordination with the UAAC, will present a quarterly update on the progress of this Assessment Plan to the President and provost.

The focus of the plan for the next year will be the assessment issues and recommendations contained in the June WASC letter and the July Assessment Consultant's report.

The President, in-turn, with attention to areas of particular concern, will provide guidance to the faculty and administration and will use appropriate information from the presentation to update the Chancellor and Board of Trustees on the University's assessment efforts.

\section{Process}

Though the vision of this plan was to move toward academic assessment as a continuous process supported by an extensive and easily accessible and usable data base that allows all echelons of assessment across the university to assess and analyze data at any time, the current process is focused on doing assessment annually (PAR) and in five year segments (5 year plan). Since both the faculty and administration have a one year PAR and five year 5-Year Plan mind-set and current assessment training and assessment data collection are based on these cycles, the strategy of this plan is to acknowledge this mindset and training and data reality while moving in increments to the continuous, anytime assessment model.

As this plan was written, National University was in the process of moving from a paper report to an online data base in which data was moved into the data base from both faculty and administrative sources. A major component of the NU Assessment Program is the PAR (Program Annual Review) for which the Lead Program Faculty provides information divided into five sections are:

- $\quad$ Section I: Program Information. Program information is matched to the NU General Catalog

- $\quad$ Section II: Faculty Profile. Summary analysis of faculty information from OIRA data to include:

- Faculty Qualifications

- University Training

- Scholarship and related professional contributions

- Student course assessment

- $\quad$ Section III: Student Profile to include

- Summary analysis data from OIRA

o Recommendations

- Comparative program, school, and University data 
- $\quad$ Section IV: Class Data to include

- Average class data

- Faculty/Student ratios

- Section V: Program Assessment to include

- Program and Mission goals alignment

- Online and onsite location data

○ Program learning outcomes assessed

- Graduate Level analysis

- Graduate Council/Undergraduate Council approval of assessment tools

- Assessment Tools reliability

- Multiple means of assessment for each outcome

L Level criteria or benchmarks (rubrics, portfolios, external licensing bodies, or professional accreditation organizations

- Summative trends or other findings

- Recommendations resulting from assessment

- Assessment plan for next year - same learning outcomes, different outcomes, additional means or benchmarking activities

- Actions based on previous year's assessment and impact on program

$\circ \quad$ Summary of the implementation of the Memorandum of Agreement for the last 5-year program review

Based on data available in AMS, the Assessment Consultant recommended that the PAR focus of the Program Lead Faculty (PLF) be Section V, Program Assessment, and that the PLF not be required to input any data already available in AMS. This proposal, which was strongly supported by the Council of Chairs to reduce the tremendous workload of their Program Lead Faculty members in the current PAR cycle, and with coordination of the representatives of the various assessment entities, was implemented.

The PAR, done each year, is complemented by a Five Year Plan and MOA which assesses a given program using evidence collected over five years and focuses on data trends, cumulative data analysis, and associated recommendations. External reviewers are sought to add objectivity to the process. For a visual of the PAR process, please see page 8 in the Executive Summary.

With the availability of the AMS system, it is the hope of Program Lead Faculty and their Chairs that the accumulation of PAR data within AMS over five years will allow the 5-Year plan analysis to be made from the cumulative PAR data collect in each of the five years for which the assessment is being made.

\section{CONCLUSION}

Members of the faculty and administration who participated in the developed of the shared governance plan developed with the objective of promoting a culture of learning and assessment excellence believe the plan achieved its objective. We believe that by clarifying the assessment structure and process for both faculty and administration, supported by a list of action items with specific milestones, a new partnership in shared governance has moved the University forward to an improved academic environment of teaching and learning. We also believe the experience of the past 10 months has resulted in a stronger bond between the faculty and the administration in which trust and respect have enhanced shared governance.

Feedback from individual faculty members indicates that the faculty believes that the learning and assessment program at National University is faculty driven and that the administration has supported the faculty's effort with resources and funding. This experiment in shared governance has, by all indicators, been a resounding success. The challenge in the coming years, as faculty and administration leaders change, is to maintain the shared governance balance that thus far has been successful in improving the assessment of learning at National University so that students who attend our institution receive the education we promise them. 


\section{AUTHOR INFORMATION}

E. George Beckwith, Ed. D. is an Associate Professor at National University, San Diego and recently gave a presentation at the Clute Conference in Las Vegas (Integrating Online Multi-media Techniques with Hybrid Classes in Accelerated Programs to Enhance Learning). He serves on the NU President's Commission for Academic Excellence, and is a member of the Faculty Senate and the Graduate Council.

Susan Silverstone, D.D.S., M.B.A. is an Assistant Professor at National University in the Department of Management and Marketing in the School of Business and Management at National University. She is a member of the NU Assessment Task force and was Chair of the Undergraduate Council Assessment Committee.

Ms. Debra Bean, M.F.A. is the Associate Provost at National University and was previously the Dean of the School of Media and Communications. She has an extensive background in working with multimedia and has been highly successful in obtaining media related grants and producing remarkably successful media projects.

\section{REFERENCES}

1. Allen, M. (2004). Assessing Academic Programs in Higher Education. San Francisco: Jossey-Bass and Anker Publishing

2. American Association of College Professors (AACP) (1995) Governance and Decision Making in Colleges and Universities - Shared Governance http://education.stateuniversity.com/pages/2014/Governance-

Decision-making-in-colleges-Universities.html

3. American Federation of Teachers (ATF) April (2009). Shared Governance. From the Internet. April 10, 2009. http://www.aft.org/topics/shared-governance/

4. Anderson, L, et al (2001). A Taxonomy for Learning, Teaching, and Assessing. New York; Addison Wesley Longman, Inc.

5. Baker, M. (2005). Assessment and Review of Graduate Programs-A Policy Statement. Washington D.C. Council of Graduate Schools.

6. Gerber, L. (2009). "Inextricably Linked" Shared Governance and Academic Freedom. From the Internet, http://aaup.org/AAUP/pubsres/academe/2001/MJ/Feat/gerb.htm April 20, 2009.

7. Mortimer, K. \& Sathdre (2007). The Art and Politics of Academic Governance. UK, Sterling Price.

8. Tierney, W. (2004). Restructuring Shared Governance in Higher Education: New Directions for Higher Education. The Johns Hopkins University Press; illustrated edition. 